\title{
PPPUD Diversifikasi Produk Kerajinan Tenun Corak Insang di Kampung Wisata Tenun Khatulistiwa
}

\section{PPPUD of Product Diversification of Corak Insang Weaving at Kampung Wisata Tenun Khatulistiwa}

\author{
${ }^{1}$ Husna Amalya Melati ${ }^{2}$ Metasari Kartika, ${ }^{3}$ Yudithya Ratih \\ 1 Prodi Pendidikan Kimia, FKIP, Universitas Tanjungpura \\ 2 Prodi Ekonomi Islam, Fakultas Ekonomi dan Bisnis, Universitas Tanjungpura \\ 3 Jurusan Teknik Arsitektur, Politeknik Negeri Pontianak \\ Korespondensi: H.A. Melati, h.a.melati@.chem.edu.untan.ac.id
}

Naskah Diterima: 29 September 2019. Disetujui: 22 Juni 2020. Disetujui Publikasi: 7 Juli 2020

\begin{abstract}
Abstact. Since established on $16^{\text {th }}$ of November 2018 as a woven tourist village area, the number of visitors in Gang Sambas Jaya, Batu Layang sub district, Pontianak City has increased, but the products provided were only woven clothes and scarves with a relatively high price, thus not all visitors are interested and can afford the products. The lack of variety of the woven derivative products with various price ranges made the income of woven craftsmen was not optimal. The community service program by PPPUD (Development Program of Regional Featured Product) team in collaboration with non-governmental group (KSM) aimed to diversify the gill-pattern woven products (as known as corak insang) in order to expand the market target and to meet visitors' demand. Community service activities included training to create a corak insang ornament pattern on screw pine-based clutches, making half-moon bags model of handbags, sewing clothes - starting from making its basic pattern, breaking patterns, cutting materials and sewing clothes, and making a pouch/pencil case using the remaining woven fabrics. The activity result showed that the partners acquired skills in producing derivative products of woven corak insang. A total of 5 people acquired skills in making half-moon bag model of handbags, 8 people acquired skills in making woven corak insang ornament pattern on screw-pine based clutches, 10 people acquired skills in making basic pattern, breaking pattern, and sewing clothes, and 15 people acquired skills in creating pouch and pencil case. It shows that more than $80 \%$ of participants have been succeeded in diversifying corak Insang woven products.
\end{abstract}

Keywords: Diversification, product, woven, corak Insang, community service.

\begin{abstract}
Abstrak. Sejak ditetapkan pada tanggal 16 November 2018 sebagai kawasan kampung wisata tenun, jumlah pengunjung di Gang Sambas Jaya Kelurahan Batu Layang Kota Pontianak meningkat, namun produk yang disediakan hanya berupa kain tenun dan syal yang harganya relatif tinggi sehingga tidak semua pengunjung berminat dan mampu membelinya. Minimnya variasi produk turunan dengan berbagai rentang harga menjadikan pendapatan perajin tenun belum optimal. Pengabdian yang dilakukan oleh tim PPPUD (Program Pengembangan Produk Unggulan Daerah) bekerjasama dengan mitra Kelompok Swadaya Masyarakat (KSM) adalah mendiversifikasikan produk tenun corak insang agar mampu memperluas pangsa pasar dan memenuhi permintaan pengunjung. Kegiatan pengabdian yang dilakukan antara lain sosialisasi, pelatihan, pendampingan dan evaluasi. Pelatihan meliputi pelatihan membuat ornamen corak Insang pada clutch berbahan dasar pandan, pelatihan membuat tas tangan jenis halfmoon bag, pelatihan menjahit baju yang dimulai dari pembuatan pola dasar, pecah pola, menggunting bahan dan menjahit baju, dan pelatihan pembuatan pouch/pencil case dengan memanfaatkan sisa kain tenun dan kain tenun yang ada. Hasil kegiatan menunjukkan bahwa mitra kemudian memiliki keterampilan dalam memproduksi produk turunan dari tenun
\end{abstract}


corak Insang. Sebanyak 5 orang memiliki kemampuan dalam membuat tas tangan model (halfmoon bag), 8 orang memiliki kemampuan dalam membuat ornamen tenun corak Insang pada produk clutch berbahan pandan, 10 orang telah memiliki kemampuan dalam membuat pola dasar, pecah pola dan menjahit baju dan 15 orang telah memiliki kemampuan membuat produk berupa pouch dan pencil case.Hal ini menunjukkan bahwa lebih dari $80 \%$ mitra telah berhasil melakukan diversifikasi produk tenun corak Insang.

Kata Kunci: diversifikasi, produk, tenun, corak Insang, pengabdian.

\section{Pendahuluan}

Corak Insang adalah salah satu motif yang menjadi ikon kota Pontianak. Corak ini diambil dari bagian tubuh ikan yaitu insang yang merupakan alat pernafasan. Masyarakat kota Pontianak dulunya banyak tinggal di sekitar sungai Kapuas dan bermata pencaharian sebagai nelayan. Corak ini kemudian banyak dituangkan pada berbagai media sebagai bentuk pengambaran nilai budaya kota Pontianak. Salah satunya pada kain tenun. Tenun corak Insang cukup banyak diminati karena merupakan kain khas kota Pontianak. Kain corak ini lebih mudah diaplikasikan dalam perpaduannya dengan berbagai warna dibandingkan tenun jenis lain yang didominasi benang emas (Melati, Ratih \& Kartika, 2017).

Kampung wisata tenun Khatulistiwa merupakan satu-satunya kawasan di kota Pontianak yang memproduksi tenun corak Insang dengan alat tenun gantung tradisional dan memiliki 17 rumah tenun didalamnya. Berdasarkan hasil orientasi lapangan dan koordinasi antara tim Pengabdian Pada Masyarakat (PPM) dan mitra diperoleh analisa terhadap need and demand penenun yang tergabung dalam Kelompok Swadaya Masyarakat (KSM). Koordinasi dengan mitra ini diharapkan menjadi masukan terkait program yang akan dilaksanakan maupun ide-ide lainnya yang dapat ditindaklanjuti sebagai upaya peningkatan kapasitas diri penenun maupun kapasitas produksi dan pemasaran untuk menaikkan omset.

Hasil analisis menunjukkan bahwa kunjungan wisatawan yang juga merupakan konsumen baik lokal, nasional dan Internasional semakin meningkat setelah wilayah ini ditetapkan sebagai kawasan kampung wisata oleh SK Walikota No. 807/DKUMP/TAHUN 2018 tentang Penetapan Kampung Wisata Tenun Khatulistiwa Kelurahan Batulayang kecamatan Pontianak Utara pada tahun 2018. Namun, produk yang diproduksi dan dijual belum sepenuhnya dapat memenuhi kebutuhan wisatawan atau konsumen pada berbagai segmentasi, padahal kerajinan tenun corak Insang memiliki potensi untuk dikembangkan sebagai subsektor ekonomi kreatif di kota Pontianak (Metasari, Melati, \& Ratih, 2019).

Pengunjung Kampung Wisata Tenun Khatulistiwa yang berasal dari berbagai kalangan dan berbagai tingkat ekonomi tentu saja memiliki daya beli yang berbedabeda terhadap produk yang disajikan. Produk tenun corak Insang yang tersedia saat ini hanya kain tenun dengan harga mulai dari Rp 400.000,00 hingga jutaanper helainya dan produk turunan berupa syaldengan harga mulai dari Rp $80.000,00$ hingga ratusan ribu per helainya. Kedua produk ini hanya dapat digunakan pada acara tertentu. Harga yang relatif mahal membuat kain tenun hanya mampu dibeli oleh pengunjung yang berpendapatan menengah ke atas sedangkan masyarakat menengah kebawah lebih memilih membeli kain tenun pabrikan. Harga yang mahal ini pula membuat tenun corak insang tidak dapat dijadikan oleh-oleh andalan yang harus dibeli oleh wisatawan. Mitra belum melakukan analisis usaha terutama tentang menemukan nilai khas produk dan segmen pasar yang memungkinkan produk berbasis tenun corak Insang dapat laku di pasaran. Penemuan ide, kendala ketersediaan modal, dan kendala dalam menemukan nilai khas produk serta segmentasi pasar menjadi beberapa hal yang menjadikan kendala dalam berwirausaha (Zamrudi, Karim, \& Wicaksono, 2018). Oleh karena itu,diperlukan strategi dalam menggapai pangsa pasar ini.

Tim PPM dan mitra menyepakati perlu melakukan strategi diversifikasi untuk menjawab persoalan ini. Menurut Hermawan (2015), diversifikasi produk dilakukan 
sebagai strategi pemasaran yang bertujuan antara lain untuk memperluas pangsa pasar, memberikan nilai tambah dan pendapatan. Lebih lanjut Le (2019) menyatakan bahwa strategi diversifikasi ini dipilih setelah mengukur secara komprehensif antara sumber daya dan kemampuan.

Kegiatan pengabdian ini bertujuan untuk meningkatkan kapasitas mitra dalam melakukan diversifikasi produk atau membuat produk turunan dari tenun corak Insang. Kapasitas mitra berupa keterampilannya dalam melakukan diversifikasi akan bermanfaat dalam memperluas jangkauan konsumen terhadap daya beli dari produk yang dihasilkan di lokasi wisata ini. Diversifikasi produk ini diharapkan dapat memberikan ragam produk sebagai oleh-oleh khas kampung wisata tenun dengan harga yang bervariasi sehingga dapat meningkatkan kesejahteraan warga Kampung Wisata Tenun Khatulistiwa. Beberapa warga sekitar ada yang memiliki kemampuan menjahit dan membuat kerajinan tangan, namun masih memiliki kelemahan dalam memvariasikan tenun untuk aplikasi berbagai produk. Oleh karena itu perlu dilaksanakan pelatihan diversifikasi produk agar mitra dapat memproduksi produk turunan dari tenun corak insang.

\section{Metode Pelaksanaan}

Tempat dan Waktu. Kegiatan pengabdian masyarakat ini dilaksanakan di Kampung Wisata Tenun Khatulistiwa yang beralamat di Jl. Khatulistiwa Gg. Sambas Jaya, Kelurahan Batulayang, Kecamatan Pontianak Utara selama delapan bulan. Untuk kegiatan diversifikasi produk dilaksanakan dalam 6 kali pertemuan dengan durasi 240 menit per pertemuan.

Khalayak Sasaran. Khalayak sasaran pada kegiatan pengabdian ini adalah para ibu dan remaja putri baik yang berprofesi sebagai perajin tenun maupun bukan perajin tenun yang tinggal di lokasi wisata. Jumlah peserta sebanyak 15 orang dipilih berdasarkan keahlian yang dimiliki yaitu keterampilan jahit dasar.

Metode Pengabdian. Metode pelaksanaan kegiatan pengabdian ini meliputi :

A. Tahap Persiapan berupa Sosialisasi Kegiatan, Focus Group Discussion (FGD) dan Rencana Kerja Tindak Lanjut (RKTL)

B. Tahap Pelaksanaan berupa Pelaksanaan Pelatihan

C. Tahap Pendampingan dan Evaluasi

Indikator Keberhasilan. Indikator keberhasilan dari kegiatan adalah terlaksananya sosialisasi kegiatan, FGD, dan RKTL yang ditandai dengan kehadiran seluruh peserta sebanyak 15 orang dan dihasilkan rundown kegiatan pelatihan. Indikator berikutnya adalah terlaksananya kegiatan pelatihan pembuatan produk turunan yaitu halfmoon, clutch, baju, dan pencil case/pouch. Dalam proses pendampingan dan evaluasi dinyatakan berhasil ketika $80 \%$ peserta dapat menghasilkan satu dari empat tiga jenis variasi produk turunan yang menggunakan tenun corak Insang sebagai souvenir atau buah tangan oleh-oleh khas Pontianak Kalimantan Barat.

Metode Evaluasi. Evaluasi terhadap kegiatan sosialisasi, FGD, dan RKTL dilakukan melalui pengisian lembar observasi keterlaksanaan kegiatan dan daftar hadir peserta. Evaluasi terhadap pelaksanaan pelatihan dilakukan melalui angket yang diberikan kepada peserta dan evaluasi pendampingan dilakukan dengan mengunakan lembar observasi pada saat peserta melakukan proses produksi dari produk diversifikasi secara mandiri. Observasi dilakukan terhadap keterampilan tiap proses, kuantitas dan kualitas produk yang dihasilkan.

\section{A. Kegiatan Sosialisasi, FGD, dan RKTL}

Kegiatan Pengabdian Pada Masyarakat (PPM) skim PPPUD ini dimulai dengan sosialisasi kegiatan termasuk di dalamnya Focus Group Discussion (FGD) dan 
Rencana Kerja Tindak Lanjut (RKTL). Kegiatan FGD dan RKTL dilakukan agar kegiatan dapat terencana dan berlangsung dengan baik sekaligus dirasakan oleh warga sebagai kegiatan yang penenun butuhkan (Metasari, Melati, \& Ratih, 2019). Sosialisasi dilakukan sebagai bentuk metode pendekatan partisipasif dan instruksional dimana tim PPM memaparkan rancangan jadwal dan kegiatan yang akan dilaksanakan (Gambar 1). Melalui sosialisasi ini diharapkan mitra yaitu para penenun maupun bukan penenun yang nantinya akan menjadi peserta dari beberapa kegiatan yang dirancang mengetahui bentuk-bentuk kegiatan yang akan dilakukan.

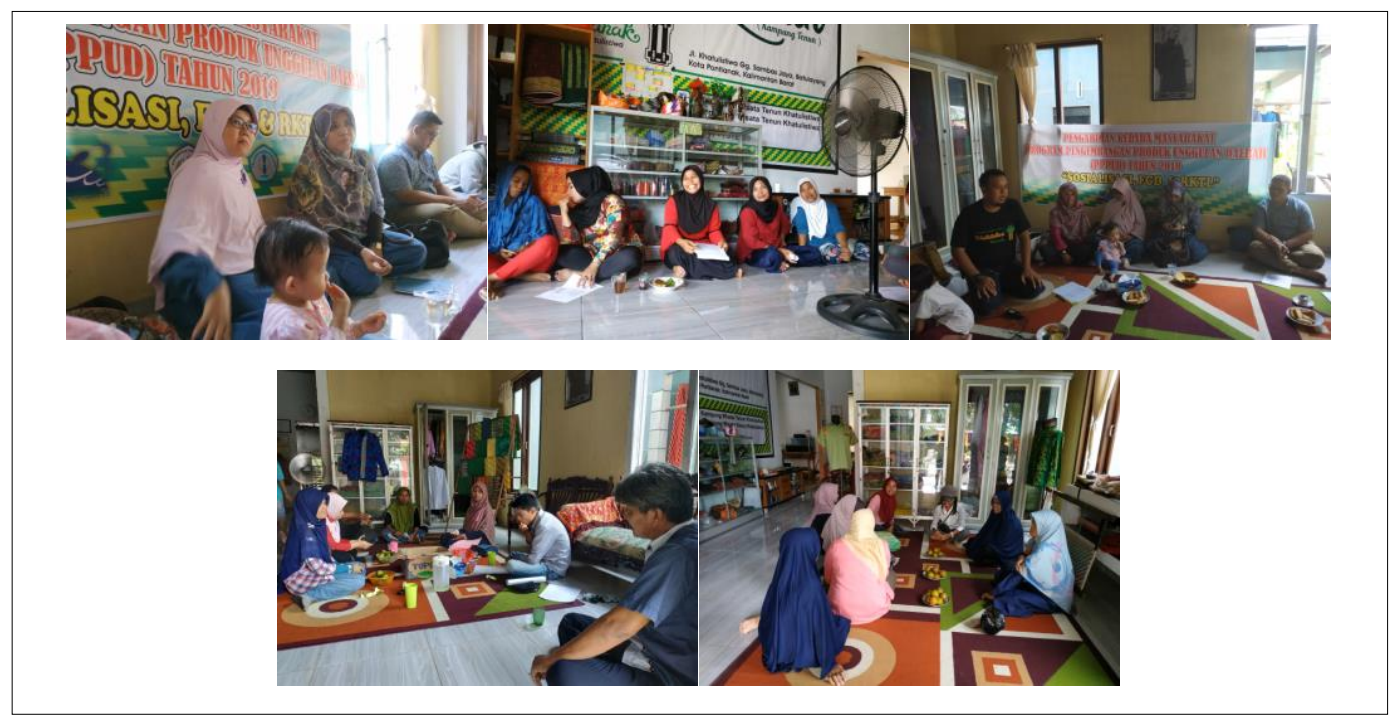

Gambar 1. Sosialisasi Kegiatan, FGD, dan RKTL

Kegiatan yang dilakukan setelah sosialisasi adalah menggunakan metode Workshop integrative atau FGD. Agar hasil dari FGD bisa terwujud secara sistematis maka kegiatan FGD yang dilakukan dibarengi dengan melakukan Rencana Kerja Tindak Lanjut (RKTL). Berlangsung di tempat yang sama dengan kegiatan sosialisasi, pelaksanaan FGD dan RKTL melibatkan mitra penenun, remaja putri di sekitar kawasan, pihak swasta dari PT. Angkasa Pura II, dan dari beberapa mahasiswa yang melakukan penelitian tugas akhir di kampung tenun. Dalam FGD yang dilakukan, penenun diminta menyampaikan kendala yang dihadapi selama ini yang diharapkan dapat diurai dalam bentuk kegiatan.

Bertempat di rumah ketua Kelompok Swadaya Masyarakat (KSM) Mekar II, ibu Kurniati, kegiatan PPM dipusatkan. Meski penenun terbagi ke dalam beberapa KSM, namun dalam pelaksanaan produksi dan pemasaran, semuanya terpusat pada lokasi rumah ibu Kurniati.Ibu Kurniati menjadi penggerak ibu-ibu penenun lainnya baik dalam upaya menyemangati para penenun maupun memberikan peluang untuk mempromosikan hasil tenunannya. Hasil tenun dan produk turunannya dipajang di etalase rumahnya yang sekaligus sebagai galeri hasil produksi berbagai produk warga kampung tenun lainnya.

\section{B. Pelaksanaan Pelatihan}

Produk yang selama ini dihasilkan oleh penenun adalah kain tenun corak insang dalam bentuk lembaran kain ukuran $2 \mathrm{~m} \times 1 \mathrm{~m}$. Produk yang dihasilkan secara ekonomi sasarannya lebih kepada masyarakat ekonomi menengah karena harganya cukup mahal. Selain harga, penggunaan kain ini juga terbatas pada waktu-waktu tertentu. Oleh karena itu perlu dilakukan diversifikasi produk yang dapat dijangkau oleh masyarakat dan produk yang dihasilkan juga bervariasi. Variasi produk diharapkan dapat menjadi pilihan bagi masyarakat lokal Pontianak 
maupun wisatawan domestik dan mancanegara sebagai souvenir dan oleh-oleh.

Pelatihan diversifikasi produk merupakan rangkaian kegiatan yang dilaksanakan dalam pengabdian ini didasarkan pada kemampuan para penenun yang selama ini belum dapat melakukan proses diversifikasi tenun menjadi produk souvenir dengan rentang harga yang cukup variatif. Beberapa kegiatan dilakukan agar mitra dapat memiliki keterampilan dalam diversifikasi produk antara lain pelatihan membuat ornamen corak Insang pada clutch berbahan dasar pandan, pelatihan membuat tas tangan jenis halfmoon bag, pelatihan menjahit mulai dari pembuatan pola dasar, pecah pola, menggunting bahan dan menjahit baju, dan pelatihan pembuatan pouch/pencil case dengan memanfaatkan sisa kain tenun maupun kain tenun yang ada.

Produk yang dibuat adalah tas tangan serta beberapa produk yang berbahan dasar anyaman pandan antara lain clutch, kotak pensil, dan tas laptop. Untuk pembuatan tas, sudah dilakukan persiapan yaitu membeli peralatan yang dibutuhkan terutama mesin jahit yang kemudian nantinya akan digunakan oleh warga penenun maupun warga setempat yang memiliki kemampuan menjahit dalam menghasilkan produk turunan. Produk yang berbahan dasar anyaman pandan dikreasikan dengan memberikan ornamen kain tenun corak Insang pada bagian tertentu (Gambar 2). Dari segi kajian mata rantai ekonomi dari produk ini diharapkan akan menjawab tantangan pasar yang semakin dinamis.

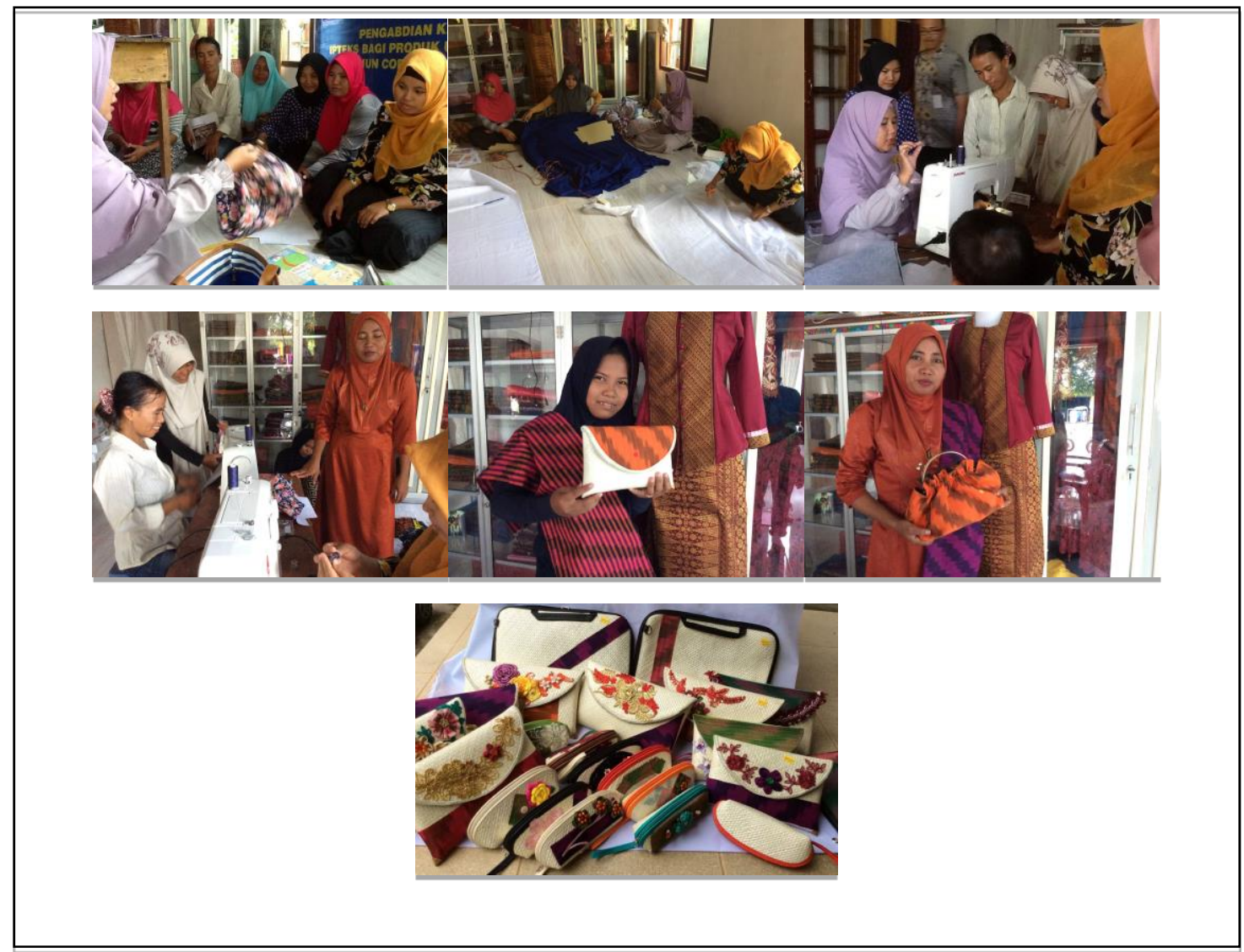

Gambar 2. Pembuatan tas, cluctch, pencil case, dan tas laptop

Bentuk diversifikasi yang dibutuhkan dan diharapkan oleh para penenun di kawasan kampung tenun atau lokasi mitra adalah pembuatan baju (fashion). Selain untuk dapat mengembangkan variasi produk turunan berbahan tenun corak Insang, para penenun berharap dapat memproduksi baju seragam yang dibutuhkan untuk menyambut kunjungan wisatawan terutama pada saat pameran 
dilakukan. Hal ini dibutuhkan untuk menunjukkan eksistensi para penenun di kawasan kampung tenun. Pelatihan dilakukan selama tiga kali pertemuan dan diikuti dengan pendampingan. Pada pertemuan pertama dilakukan pelatihan pembuatan pola dasar, dilanjutkan pertemuan berikutnya pelatihan pecah pola, dan diakhiri di pertemuan ke tiga adalah mengaplikasikan pola pada kain dan menjahitnya menjadi baju. Peserta tampak antusias dan dapat memahami materi yang diberikan (Gambar 3). Setiap pertemuan dilakukan, semua peserta mampu menghasilkan produk yang diharapkan. Hanya saja pada saatfinishing penjahitan baju, ada sebagian yang belum dapat menyelesaikan produknya dikarenakan waktu yang terbatas dan unit mesin jahit yang digunakan terbatas.

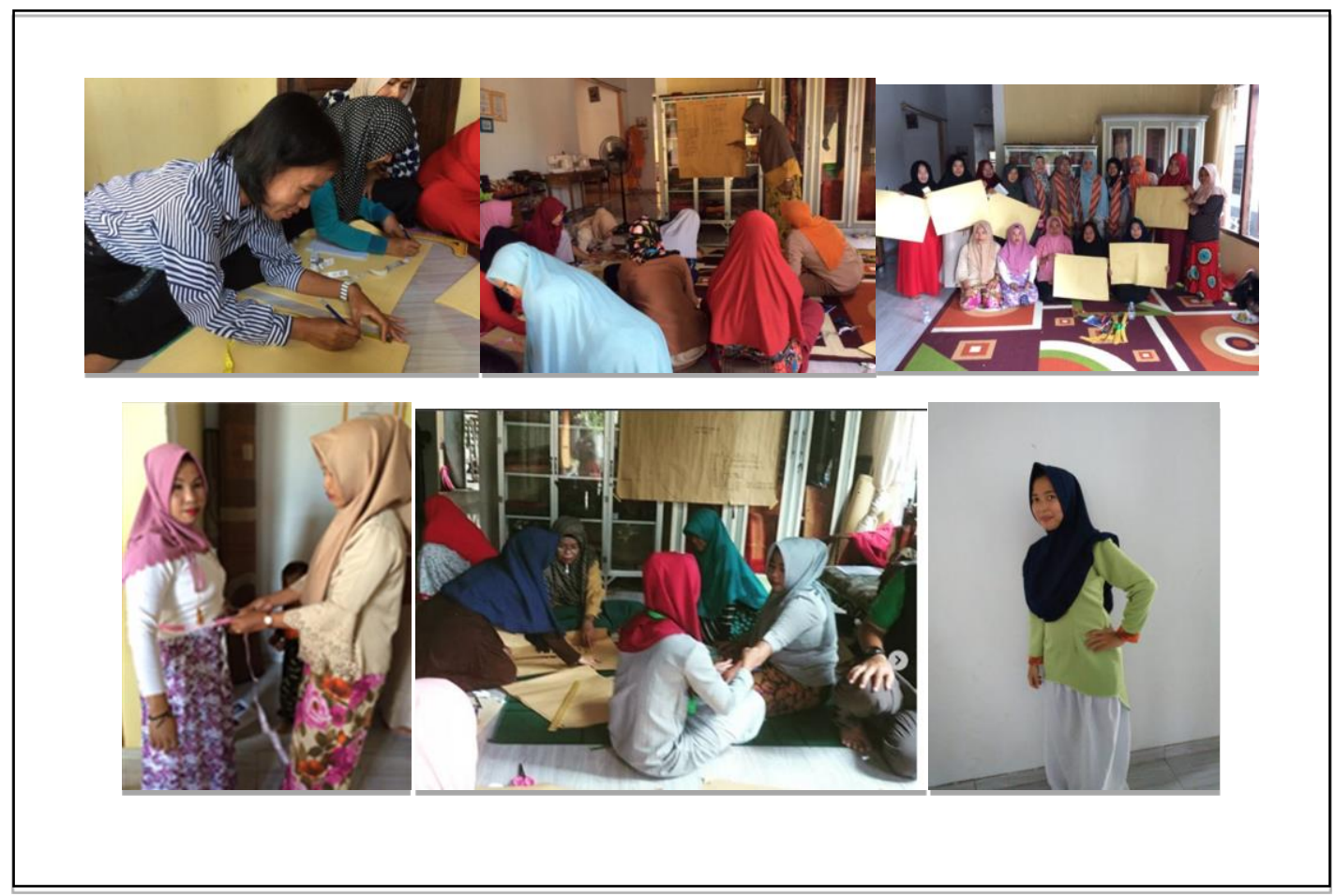

Gambar 3. Pembuatan Pola Dasar, Pecah Pola, dan Menjahit

Kegiatan pelatihan membuat pouch/pencil casediikuti ibu-ibu dan remaja putri yang ada di lokasi mitra. Kegiatan diawali dengan pemberian tutorial langkahlangkah membuat pencil case/pouch oleh narasumber yang berasal dari tim PPM. Peserta diajarkan untuk membuat pola terlebih dahulu dengan ukuran yang disesuaikan dengan kebutuhan. Peserta juga diberi kesempatan memilih bentuk dan desain ornamen tenun yang akan dikombinasikan pada produk yang akan dibuat. Kegiatan dilanjutkan dengan memotong bahan berupa kulit sintetis dan kanvas sesuai pola yang sudah dibuat. Tutorial diberikan meliputi langkah dalam menjahit retsluiting, menempelkan/menjahit bagian tenun sebagai ornamen pada produk yang dibuat, menjahit handle dan ring $\mathrm{D}$, menjahit label merek produk yaitu Kanun sebagai identitas produk berasal dan menjahit untuk membuat bentuk dari pencil case/pouch.

Peserta sangat antusias dalam mengikuti kegiatan. Dengan peralatan mesin jahit portable sebanyak empat buah, peserta dapat menjahit produknya secara bergantian. Hasil menunjukkan bahwa seluruh peserta dapat membuat produk diversifikasi berupa pencil case/pouch dengan baik. Tingkat kerapihan jahitan berbeda-beda namun secara prinsip, peserta telah dapat membuat produk tersebut sesuai dengan langkah-langkah yang diberikan (Gambar 4). Terlihat ada peserta yang membuat variasi bentuk dari ornamen tenun yang diberikan pada produk 
selain yang dicontohkan oleh pemaveri. Produk yang telah berhasil dibuat oleh peserta kemudian dipersiapkan untuk dibawa pada pameran produk unggulan daerah.

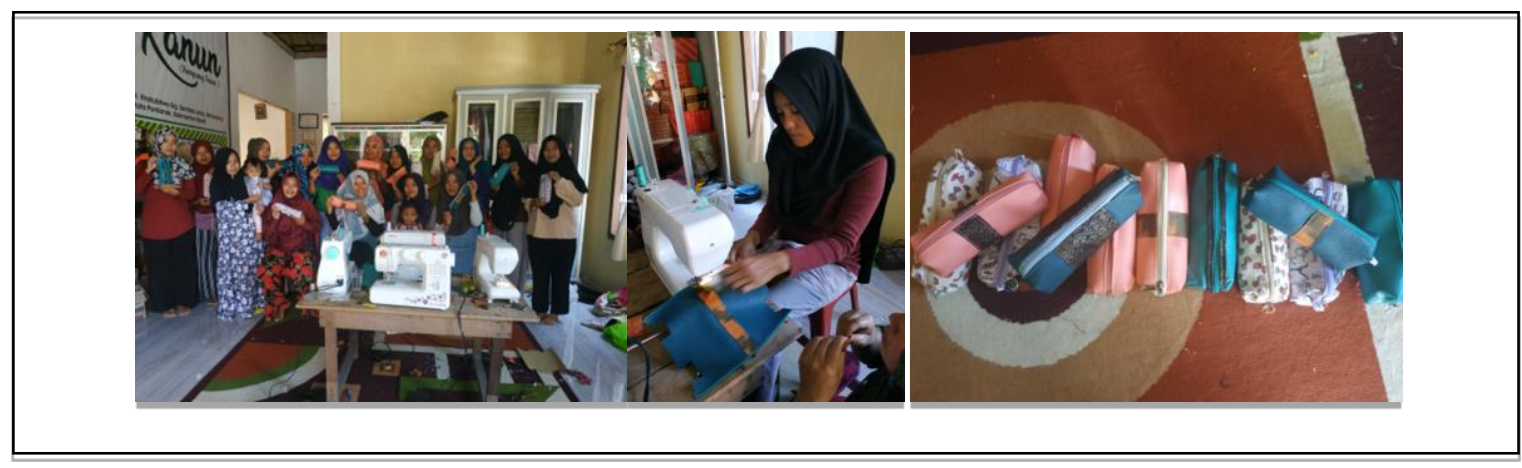

Gambar 4. Pembuatan Pouch/Pencilcase

\section{Pendampingan dan Evaluasi}

Setelah kegiatan pelatihan dilakukan, pendampingan dilakukan dengan cara terus melakukan koordinasi dan komunikasi dengan mitra agar terus semangat memproduksi turunan produk dari tenun corak insang dikarenakan diversifikasi produk ini bermanfaat untuk menjangkau pangsa pasar. Hasil dari pendampingan saat ini di etalase Kampung Wisata Tenun Khatulistiwa telah tersedia produk turunan berupa clutch, pencil case, tas, baju, dan pouch dengan harga yang lebih bervariasi kisaran Rp 30.000,00 - Rp 300.000,00 selain kain dan syal. Kegiatan ini dapat dikatakan berhasil dikarenakan peserta dapat membuat salah satu dari empat jenis variasi produk turunan yang menggunakan tenun corak Insang sebagai souvenir atau buah tangan oleh-oleh khas Pontianak Kalimantan Barat dan meningkatnya keterampilan peserta kegiatan dalam melakukan diversifikasi produk tenun corak Insang.

\section{Keberhasilan Kegiatan}

Evaluasi dari kegiatan ini adalah peserta hadir dan aktif dalam pelaksanaan sosialisasi, FGD, dan RKTL sehingga kegiatan pelatihan dapat dilaksanakan sesuai rundown yang disusun bersama. Pelatihan telah berhasil dilaksanakan yang meliputi pelatihan membuat halfmoon bag, clutch, baju, dan pencil case/pouch. Hasil pendampingan diperoleh hasil bahwa peserta sudah memiliki keterampilan dan kreativitas dalam menciptakan produk turunan dari tenun corak Insang. Sebanyak 5 orang memiliki kemampuan dalam membuat tas tangan model (halfmoon bag), 8 orang memiliki kemampuan dalam membuat ornamen tenun corak Insang pada produk clutch berbahan pandan, 10 orang telah memiliki kemampuan dalam membuat pola dasar, pecah pola dan menjahit baju dan 15 orang telah memiliki kemampuan membuat produk berupa pouch dan pencil case. Hasil diversifikasi produk ini sudah mampu terjual di etalase Kampung Wisata Tenun Khatulistiwa, sosial media (facebook dan instagram Kanun) dan bazar-bazar yang diikuti oleh mitra. Hanya saja beberapa produk seperti pencil case atau pouch perlu perbaikan kualitas kedepannya terkait kerapihan dalam menjahit ornamen pada bahan kulit sintetis.

\section{Kesimpulan}

Kegiatan pengabdian yang dilakukan telah berhasil melakukan sosialisai, FGD, dan RKTL kepada seluruh peserta, sehingga diperoleh rundown pelaksanaan kegiatan yang disepakati bersama. Hasil pelatihan dan pendampingan menunjukkan bahwa lebih dari $80 \%$ mitra dapat memproduksi minimal satu dari empat produk turunan dari corak insang yakni halfmoon bag, clutch berbahan 
pandan, baju, pencil case atau pouch. Hasil diversifikasi produk ini selanjutnya dijual di etalase Kampung Wisata Tenun Khatulistiwa, sosial media (instagram dan facebook) Kanun, dan bazar-bazar yang diikuti mitra. Tentu saja dengan adanya diversifikasi produk ini memberikan tambahan pendapatan bagi mitra.

\section{Ucapan Terima Kasih}

Artikel ini merupakan salah satu hasil dari Program Pengabdian kepada Masyarakat dengan skim Program Pengembangan Produk Unggulan Daerah (PPPUD). Oleh karena itu diucapkan terimakasih kepada Direktorat Riset dan Pengabdian Masyarakat (DRPM), Direktorat Jenderal Penguatan Riset dan Pengembangan Kementerian Riset, Teknologi, dan Pendidikan Tinggi yang telah mendanai kegiatan pengabdian ini. Ucapan terimakasih juga kepada pimpinan Institusi, Pemerintah Daerah Kota Pontianak, KMW OC-3 KOTAKU, BKM Pilar Khatulistiwa, BDC Zamrud Khatulistiwa, dan mitra KSM Mekar II dan KSM Pucuk Rebung yang telah mendukung kegiatan pengabdian ini.

\section{Referensi}

Hermawan, L. (2015). Dilema Diversifikasi Produk: Meningkatkan Pendapatan atau Menimbulkan Kanibalisme Produk?.Jurnal Studi Manajemen. Vol. 9, No.2, pp. $142-153$.

Le, H. (2019). Literature Review on Diversification Strategy, Enterprise Core Competence and Enterprise Performance. American Journal of Industrial and Business Management, Vol.9, pp. 91-108.

Melati, H.A, Ratih, Y., \& Kartika, M. (2017). Peningkatan Kapasitas Penenun Corak Insang Melalui Pelatihan Motivasi Usaha dan Menganik. Abdimas Talenta 2(2):109-114.

Melati, H.A, Ratih, Y., \& Kartika, M. (2019). Pelatihan Teknik Pencelupan dan Pengikatan Warna Benang Kepada Perajin Tenun Corak Insang di Kota Pontianak. International Journal of Community Service Learning. Vol 3, Number 3, pp. 138-144

Metasari, K., Melati, H.A., \& Ratih, Y. (2019). The Development of Corak Insang Weaving Craft Creative Economy in Pontianak City. Malaysian E Commerce Journal, 3(2) : 27-29

Zamrudi, Z., Karim, K., \& Wicaksono, T. (2018). Workshop Business Model Canvas untuk Analisa Bisnis Komprehensif. Jurnal Panrita Abdi, 2(2), 105-112.

Penulis:

Husna Amalya Melati, Program Studi Pendidikan Kimia, Fakultas Keguruan dan Ilmu Pendidikan, Universitas Tanjungpura, Pontianak.E-mail: h.a.melati@chem.edu.untan.ac.id

Metasari Kartika, Program Studi Ekonomi Islam, Fakultas Ekonomi dan Bisnis, Universitas

Tanjungpura, Pontianak. E-mail:metasarikartika@ekonomi.untan.ac.id

Yudithya Ratih, Jurusan Teknik Arsitektur, Politeknik Negeri Pontianak. E-mail:yudratih@gmail.com

Bagaimana men-sitasi artikel ini:

H.A. Melati., Metasari, K., \& Yudithya, R. (2020). PPPUD Diversifikasi Produk Kerajinan Tenun Corak Insang di Kampung Wisata Tenun Khatulistiwa. Jurnal Panrita Abdi, 4(3), 314-321. 